\title{
Fragile Edges and Floating Strategies along the Albanian Coastline
}

\author{
Loris Rossi, Laura Pedata, \\ Enrico Porfido, Giuseppe Resta
}

\begin{abstract}
The essay investigates coastline development along the southern area of the Albanian Riviera, introducing the concepts of "landscape fragments" and "landscape within a landscape" as design methodologies. By speculatively reversing the order of landscape perception from land to water, the coastline becomes a flexible device capable of responding to unpredictable future events - natural disasters related to climate change (rising sea levels), or globally challenging socio-political phenomena (such as mass migration growing in scope, complexity and impact). The experimental design approach involves the design and representation of an incremental waterscape. By reversing the morphological perception of the coastal landscape and making a set of tactical selections in natural and artificial landscapes, the students highlighted the territory's potential. With new awareness, they proposed site-specific interventions along the coast and inland, re-territorializing the "apparent tabula rasa" and demonstrating the coastline's potential dynamic reaction to environmental challenges.
\end{abstract}

Keywords: Albanian riviera, floating strategies, fragile edges, hybrid projects, landscape fragments

In 1972, Fernand Braudel referred to the Balkans, which he saw as part of the Mediterranean peninsula, together with Anatolia and North Africa, as '[...] 'mountain islands,' independent but isolated, regarded with suspicion and having very little access to the outside world [...]." ${ }^{1}$ Following 
Braudel's intuition, what if we were to consider the Albanian coastline, not as a single tract of land, but rather as a set of "mountain islands," small villages surrounded by a green sea? If we do, the whole green strip facing the Adriatic and the lonian seas essentially becomes an "archipelago of architectures in a green lagoon of natures," ${ }^{2}$ where the villages spread over the landscape are isolated points connected by a hypothetical "green glue" shaped by slow paths and winding roads. Following this intuition, the need to address issues related to landscape resilience becomes an opportunity to research new possible operative morphologies that work with autonomous fragments floating in a "green sea," where perceptions of seascape and landscape are inverted, generating new scenarios in an emerging new landscape. The green strip between the Riviera road and the coastline could then be seen as a "fragile podium," where "hybrid morphologies" can overturn the meaning of seascape and landscape. The domain of the mainland can establish a creative contradiction with the domain of the waterscape.

To set the background for the main topic of this essay, we should specify the character and the condition of the Albanian landscape in the strip of coastline between the Llogara National Park and Nivice village (Fig. 1), also known as Albanian Riviera. ${ }^{3}$ From a broader perspective, this coastal

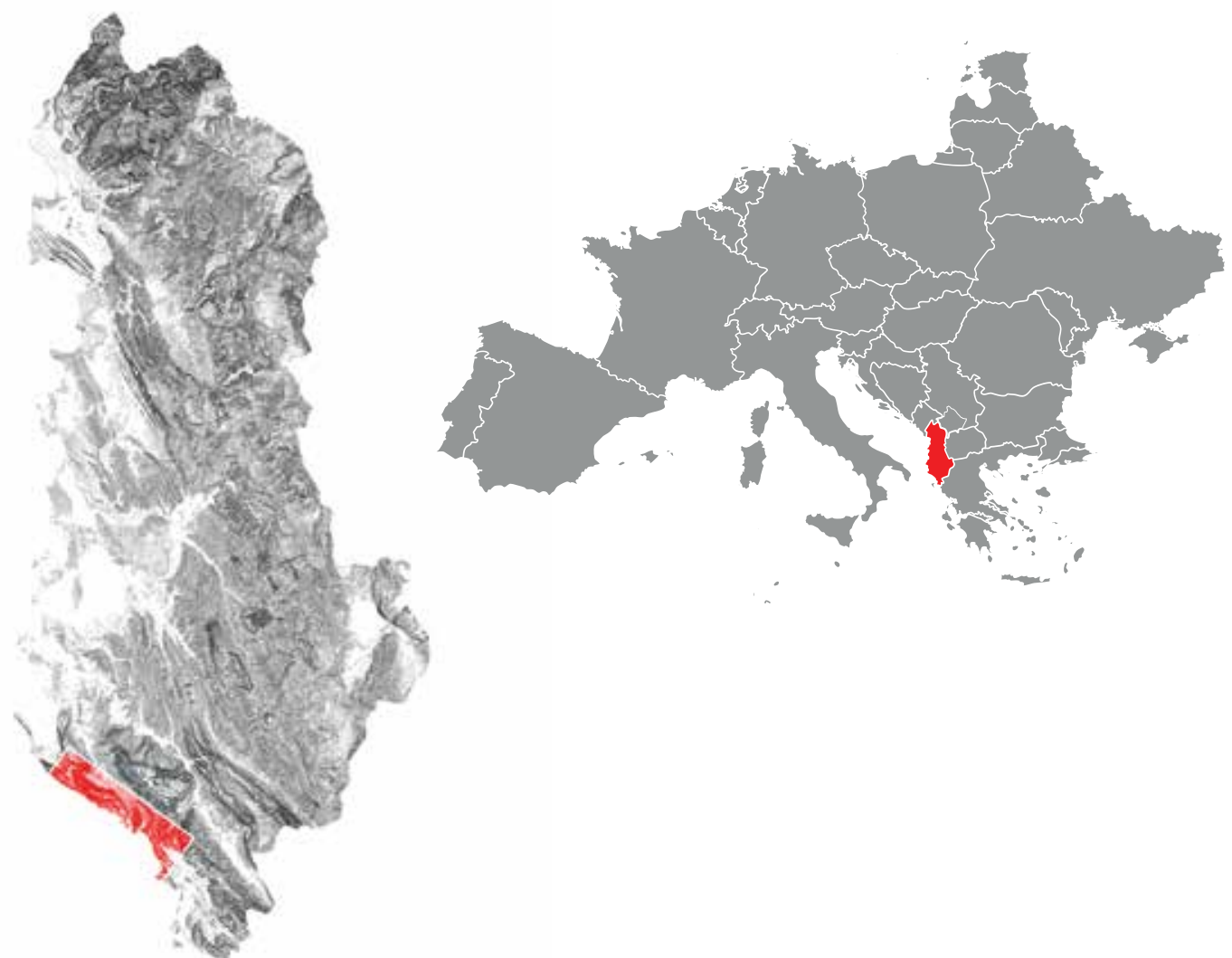

Figure 1. Research project area: the southern coast of Albania from the Llogara National Park to Nivice village, also known as the Albanian Riviera (upper right: Albania and Kosovo within continental Europe). 
segment is in continuity with a larger European infrastructure that joins a number of cities from Slovenia to Greece. Due to its political isolation, the Albanian Riviera has always represented the "missing link" between northern and southern Balkan countries facing the Adriatic and Ionian seas. Its geographic location highlights the importance of this connection for the country's economic development, not only in terms of its touristic potential. The coastal area of Albania, stretching for about $330 \mathrm{~km}$ [205 mi.] from north to south, is characterized by lowlands and wide coastal plains in the north and a mostly rocky coast with some alluvial plains in the south, such as Qeparo and the Butrint Lagoon. ${ }^{4}$ The study area is strongly characterized by a mountain system that has had, until now, the role of preserving the natural ecosystem, acting as a physical-morphological barrier against human invasion. Indeed, the Riviera's lack of urbanization is mainly due to its difficult accessibility. The Albanian Riviera is characterized by the alternation of natural and artificial landscapes, which makes the area interesting from both an environmental and a cultural point of view. The fil rouge connecting those features is the national road $\mathrm{SH} 8$, a slow path stretched between the remote villages and the natural heritage. Driving along the Riviera Road, which offers panoramic breath-taking views, we can better understand the peculiarity of this site. Nowadays, the existing villages are strongly affected by seasonal touristic activities. In summer, an increasing number of tourists challenges those settlements' receptive capability; while winters offer a desolate panorama made of ghost villages. This phenomenon also affects the local architecture, which tries to rapidly adapt to shifting needs. In fact, the buildings' shape is transformed by a number of architectural additions, resulting in an obvious contradiction between traditional and contemporary architecture.

Taking into consideration these weak points, the debate on the Albanian Riviera is mainly aimed at defining strategies to improve the existing services and infrastructures adapting them to seasonal changes. Nevertheless, due to its peculiar morphology, characterized by sudden drops in level, the area represents an interesting challenge when dealing with climate change.

Three years ago, our Department of Applied Research at Polis University in Tirana observed the Albanian government's great interest in this strip of land and water - an interest that later resulted in the organization of international competitions ${ }^{5}$ and design proposals. Having decided to establish the first unit - the Observatory of the Mediterranean Basin, ${ }^{6}$ entirely committed to the observation and investigation of all phenomena related to water and land issues in the Mediterranean basin, we initiated a set of studies and speculations on the Albanian coast. ${ }^{7}$

The strip of Albanian coastline land that is the object of our reflection appears to be unique in terms of orography and nature. Its configuration confers a sense of temporariness, indeterminacy and even imprecision, probably generated by the blurred edge between the existing villages 
and the dense surrounding greenery. It is through Fernand Braudel's intuition that the hidden frame of this tract of the Albanian landscape can be revealed: the secret to understanding the beauty of this landscape lies in the simple act of inverting the common attitude toward the perception of sea-form and land-form. As Braudel pointed out, the "mountain islands," "independent but isolated," lie along a fragile border, a device in which seascape and landscape can invert their main morphology and natural characteristics. The southern Albanian Riviera can be considered as an isolated area with very limited access from and to the outside world. The landscape is engraved by the slow Riviera Road that winds its way through mountains and across plains, held up against a natural podium with the sea as a background. For centuries, these two elements, the Riviera Road and the natural podium, have been the main characterizing elements of the Mediterranean basin. The edge defined by the coastline outlines the Mediterranean basin and is made up of several different landscape typologies. On one side, the strip engages the fluidity of the sea; on the other, it reacts to the unpredictable mutations of the land caused by natural events and human activities.

The main aim of this study is to investigate the strip between the Riviera Road and the coastline, an area of land that creates a natural podium, open to the continuous mutation of the sea. Within this framework, we consider the mechanism of an "inverted landscape" (between land and water) and apply it to a design expedient; the resultant topographical representation suggests possible strategies to respond to unpredictable events along the Albanian coastline. Profound changes in our society and the environment prove the importance of observation, investigation and the integration of traditional methods of architectural design with theoretical tools from multiple disciplines. The edge between land and water must be seen as a way to identify and meditate upon different types of crises, including the effects of rising sea levels and flooding as well as the movements of people - both "gentle invasions" from tourists and the mass migration that is growing in scope, complexity and impact. To understand the logic behind this investigation, we must introduce two hypotheses.

The first hypothesis is that, for the first time, the Albanian Riviera is not the object of a unitary plan; on the contrary, it is considered in terms of "landscape fragments." The topic of fragmentation is connected to the operative meaning of being "interrupted," a tool able to connect something that "was" with something that "could be." In some contexts, urban and political activities inherited from the past have activated dynamic transformations of the landscape. ${ }^{8}$ Within these transformations, architecture has played a pivotal role in the identification of typological and morphological characteristics of the Albanian landscape.

The second hypothesis takes into consideration the possibility of identifying a "landscape within a landscape." Many of these concepts can be traced 
back to the theories formulated by Oswald Mathias Ungers and his colleagues in the well-known manifesto The City in the City. Berlin: A Green Archipelago (2013), ${ }^{9}$ which uses this hypothesis as a background methodology. The relevance of this work to our research reveals itself not in our result, but in the process of identification and selection of all the operative artificial and natural morphologies that act as a "green glue." In this context, the sea and the land can be defined as an operative background where we can identify relevant objects or superimpose new landscape projects.

The coastal strip is shaped by diverse autonomous objects, including the Riviera Road, the river systems, the villages and the artificial agricultural terraces, all surrounded by wilderness. These elements can become operative as soon as they are incorporated into the system that we call "archipelago." 10 We applied the idea of archipelago - a system made up of autonomous islands - as a design strategy to choose landscape elements (both natural and artificial) and transform them into operative fragments. These elements are design actions with a double objective: on the one hand, they allow us to recognize and reinforce the existing uniqueness of the Albanian landscape; on the other, they enable us to identify new hybrid architecture within the Albanian landscape and seascape.

The arguments that follow define a methodology whereby the concept of an archipelago, standing on a fragile podium, can become a tool to operate architectural speculations and help open new debates about the resilience of the Albanian coastline.

\section{LANDSCAPE FRAGMENTS}

The main objective of this research was to collect several different design ideas for each area of land. The Riviera was therefore divided into nine strips and made the subject of an "Exquisite Corpse," 11 a surrealistic exercise in which, instead of proposing a unitary vision, the projects along the coast are defined as independent fragments. This exercise sprang from the ideas of André Breton, who started exploiting the mystique of imprecision with a group of artists in the first half of the twentieth century. The abstract game led to a collage, a collection of words and/or images that were collected without following a predetermined plan. The scope of this game was to leave room for each participant to express his or her individuality. Each fragment portrayed a personal reflection or individual desire, and all the fragments added up to some sort of democratic mosaic. In our design investigation, this kind of operation was reinterpreted as a landscape project, focusing its attention on an architectural rather than a territorial scale. We believe that these fragments help to rediscover existing peculiarities of the Albanian landscape. As the work progressed, the concept of "fragmentation" became associated with the idea of "archipelago" and worked as a device able to generate new coastline configurations. The archipelago shares with the natural and artificial 
elements of the landscape the characteristic of being composed of autonomous systems that can work in synergy (Fig. 2).

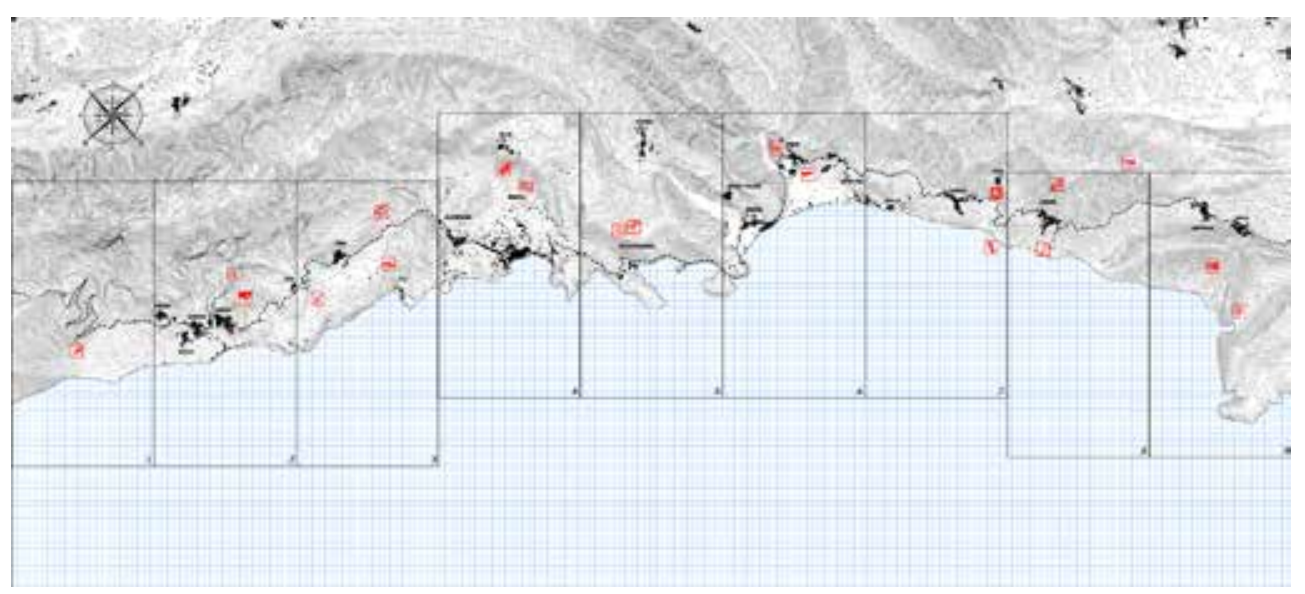

Figure 2. Map of the existing conditions of the Albanian Riviera, divided into nine strips to represent the archipelago fragments.

\section{A LANDSCAPE WITHIN A LANDSCAPE}

Having explained why we chose to work with fragments, we need to explain how to recognize an autonomous object and, most of all, how to make it work in an archipelago landscape or seascape. This need is addressed by introducing the idea of "a landscape within a landscape," a concept very similar to that of the "a city within a city" developed by Oswald Mathias Ungers and his group of brilliant students. In our case, the fundamental aspect is to examine a complex landscape and select from it flexible elements, natural or artificial, that can expand or reduce its morphological characteristics. The example shown in the images (Fig. 3) attempts to demonstrate how graphical interpretations can lead to the creation of new topographical maps that show the hidden characteristics of the landscape. The three fragments represent three different morphologies: the river system, the valley and the canyon.

These "tactical selections" enable us to re-establish relationships between land morphologies and design actions. They put us in a position to create a set of key design actions, inspired by the peculiar morphological characteristics of the landscape. We now have a range of generic tools, selected within a complex landscape and able to generate new forms of hybrid architecture. Figure 8a shows the abacus of morphologies, or taxonomy of operative elements, developed during the study. We can strengthen the strategy to work with tactical selections within a complex landscape by looking at it with the eye of a biologist. In biology, "selection" is defined as "a process in which environmental or genetic influences determine which types of organisms thrive better than others, regarded as 
a factor in evolution." ${ }^{12}$ This definition reinforces the use of the term in the context of our research if we consider it as a process of the identification and evolution of land morphologies.

The act of collecting a set of operative tools, selected from the land or the water, links the meaning of "archipelago" with its inner structure.

The tactical selection is a graphical expedient that allows us to include or exclude portions of the territory, and to highlight objects that can be autonomous and flexible at the same time. In other words, the meaning of
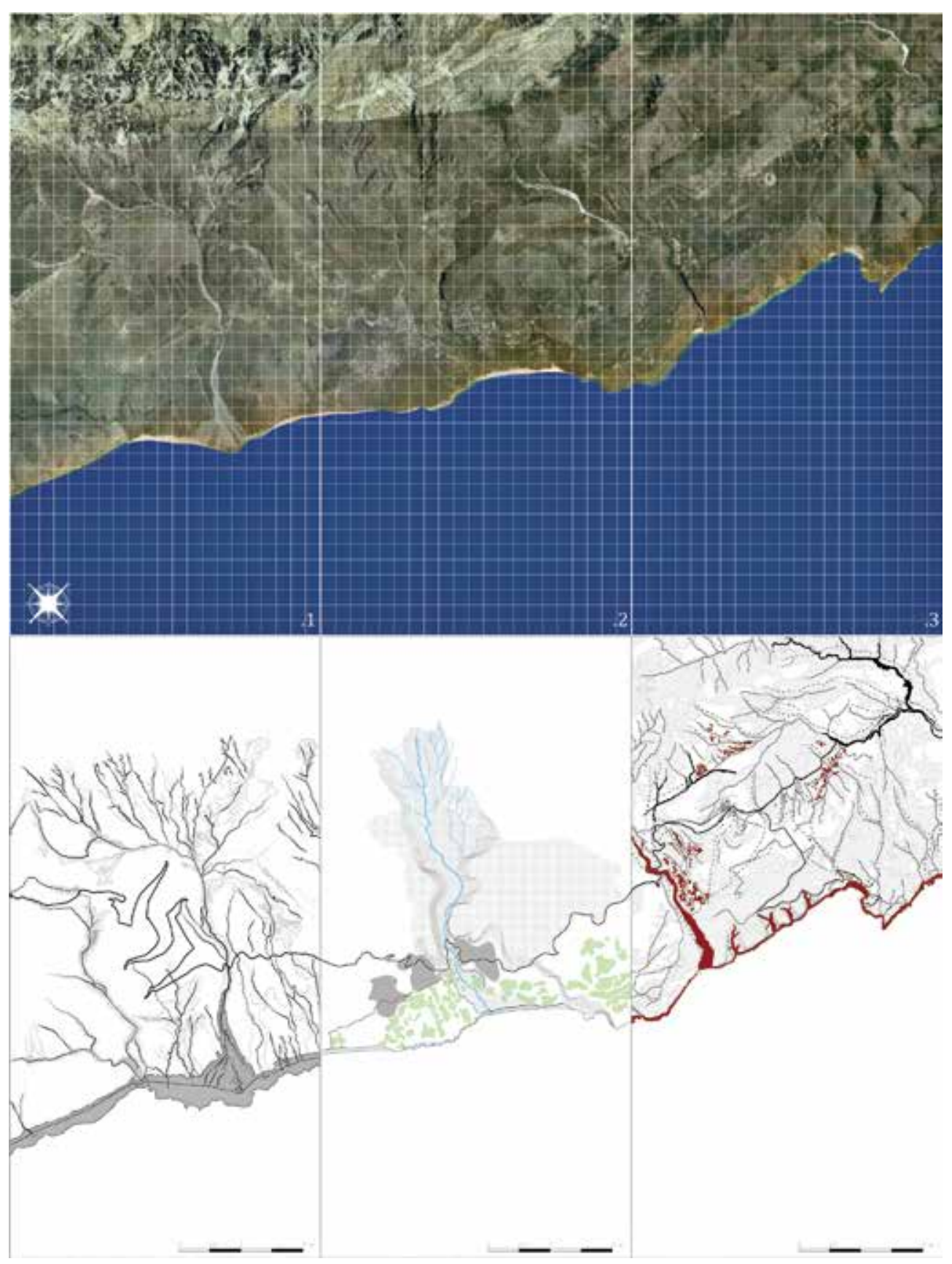

Figure 3. Aerial views and tactical selections of Fragments 1, 2 and 3. 
a tactical selection is also traceable in the meaning of operative islands. Each tool shown in Figure $8 a$ is a representation of a natural condition examples include canyon, plateau, valley and threshold - adopted as a basis for design actions.

Once these considerations have been made, the identification of "a landscape within a landscape" - the selection of a clear morphology against the water or land background - becomes clearer. To recognize one, we must learn to work with the mechanism of figure and background.

\section{ARCHITECTURE IN A GREEN SEA}

Just as we cannot speak of an archipelago in the absence of a sea, we cannot identify autonomous objects in a sea of complexity unless we have a clear background. In our research, this simple comparison denotes a fundamental precondition to demonstrate how the domains of sea and land can share the same concept of background. To explain this further, we need to consider the negative aspects of water and vegetation, their capacity to erase, attack or erode things that cross their path. It is exactly at these moments of collision that both water and land create reciprocal interdependence. The background, then, becomes a "sign of erasure."

To better comprehend the concept of "reciprocal interdependence created by a device that erases," we can turn to the artistic experiments conducted by artists Christo and Jeanne-Claude. ${ }^{13}$ In several of their art projects, they used an artificial background as a tool to erase, attack or erode natural and artificial masses. The act of concealing natural and artificial elements in the landscape counterintuitively reveals these very elements, directing attention toward them. In some of their land art works, they built monotone backgrounds that challenge the edge between land and water, outlining islands or wrapping buildings. Their actions on the landscape are poetic gestures; natural or artificial elements in the landscape operate as words within a sea of sentences, shaped or wrapped by an abstract device.

Our approach is similar to the one adopted by Christo and Jeanne-Claude, as we can use the power of the sea and the land by defining an abstract background that erases natural objects and artifacts. Ungers' concept of "green grid" adopts a similar strategy, but he imagines that the grid can absorb the infrastructure of Berlin:

Parts of redundant infrastructures, whose corpses now litter whole parts of the city, and other insalubrious properties should be condemned in such a pattern that, together, they would eventually form a system of nature - a green grid - a catalogue of types that range from suburb to parkland to dense forests and even to urban farmland. This nature grid would isolate the islands and establish the metaphor of a 'green' archipelago. ${ }^{14}$ 
The following paragraphs and images deal with two design approaches to waterscape and landscape. The first operates on the sea as if it were land, while the second reverses this, metaphorically assigning the characteristics of the sea to the land. Two-dimensional topographic representation is used as a tool to make normally invisible aspects visible.

\section{MULTIMODAL LANDSCAPE}

The Albanian Riviera landscape offers us the possibility to investigate the concept of "multimodality." A landscape can be considered multimodal within the concept of "landscape within the landscape" when an area of land, selected and isolated, becomes an autonomous object with flexible edges that allow it to be used in multiple ways.

To address the main objective of our investigation, we applied the idea of "multimodal landscape" to the architectural field, proposing hybrid architectural artifacts capable of absorbing exterior influences and responding to unexpected landscape mutations; again, we imagine that the sea can behave like the land and vice versa. Following this approach and using unconventional graphical tools and a new architectural approach, the Albanian Riviera is represented as an inverted landscape for the first time. Working with a multimodal landscape in the context of our research means considering the Albanian Riviera as a source of inspiration for different design approaches and modes of intervention. The different modalities we refer to are obtainable by shifting the point of view of the observer - from the sea towards the land and vice versa - to question and challenge the present value of landscape and its possible future transformations. In the design speculations below, topographic maps are used as guiding devices to assist the audience in navigating the Riviera project proposals. These are divided into two groups, corresponding to the two hypotheses, "What if the sea were to replace the land?" and "What if the land were to replace the sea?"

In the first case, the sea, characterized by its power to erase the land, becomes the protagonist. The new interventions are developed on the sea and considered as an extension of the land toward the water; we are therefore treating the sea as if it were dry land. This condition offers an advantage over operating on the land, as the fluidity of the sea allows for functions to have easy access to people, rather than people having to access the functions.

The second condition requires seeing the land metaphorically as sea, applying the concept of "selection" to an active topography and delineating a system of architectural design actions.

Most of the design experiments presented below were produced during the last three years of the Architecture Design Studio and the professional program of Landscape and Urban Design. ${ }^{15}$ Design solutions that can yield influences from both sea and land allow these projects to deal with the concept of hybrid in architecture and the urgent need to address issues related to unpredictable natural disasters. 


\section{WHAT IF THE SEA WERE TO REPLACE THE LAND?}

First, let us consider what would happen if we operated on the sea as if it were land and we shifted our point of view from the sea toward the mainland.

Sea level rise is becoming an increasingly important issue, not only in relationship to its consequences for the environment, but also due to related socio-economic implications, "particularly because the global economy relies partly on shore activities. This is especially true for the Mediterranean countries, for many of which the coastal economy is of primary economic importance." ${ }^{16}$ In addition, rising sea levels increase beach erosion, contribute to floods and storm-related damage, and increase the intrusion of salt into fresh water streams. ${ }^{17}$

Observing the two main lines that define the Albanian Riviera, the coastline and the national SH8 road, we can identify a comb-like structure that connects the hotspots related to both cultural and natural heritages. For several kilometers, these overlap, but in those places where they are separated, a series of transversal links, "the comb's teeth," reconnect them (Fig. 4). This observation offers a starting point for a formal reflection. If we consider the $61 \mathrm{~cm}$ [2 ft.] sea level rise forecast by scientists for $2100,{ }^{18}$ we must acknowledge that several of those connections will disappear (Fig. 5). The two main areas affected are the Himarë plain, a touristic area, and the Qeparo valley, important for its agricultural production. This projection offers an outstanding opportunity to reflect on a hypothetical inversion of the roles of land and sea and to design hybrid solutions for future needs, both functionally and formally. What functions could be transferred from the land - what used to be land - to the sea while retaining the innate natural aptitudes of both?

During the studio for the Master of Landscape and Urban Design, ${ }^{19}$ these assumptions were adopted as starting points for the elaboration of floating structure prototypes, aimed at strategically addressing issues

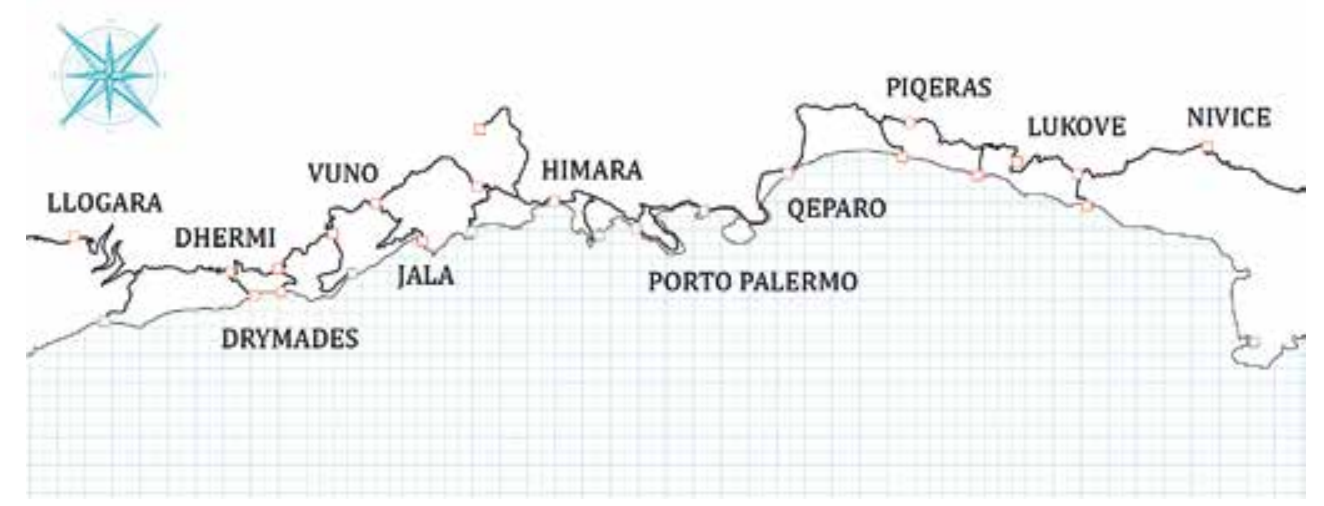

Figure 4. The "infrastructure comb" connecting the main Riviera inland hotspots-urban settlements and old villages - with the coastal points of attraction. 


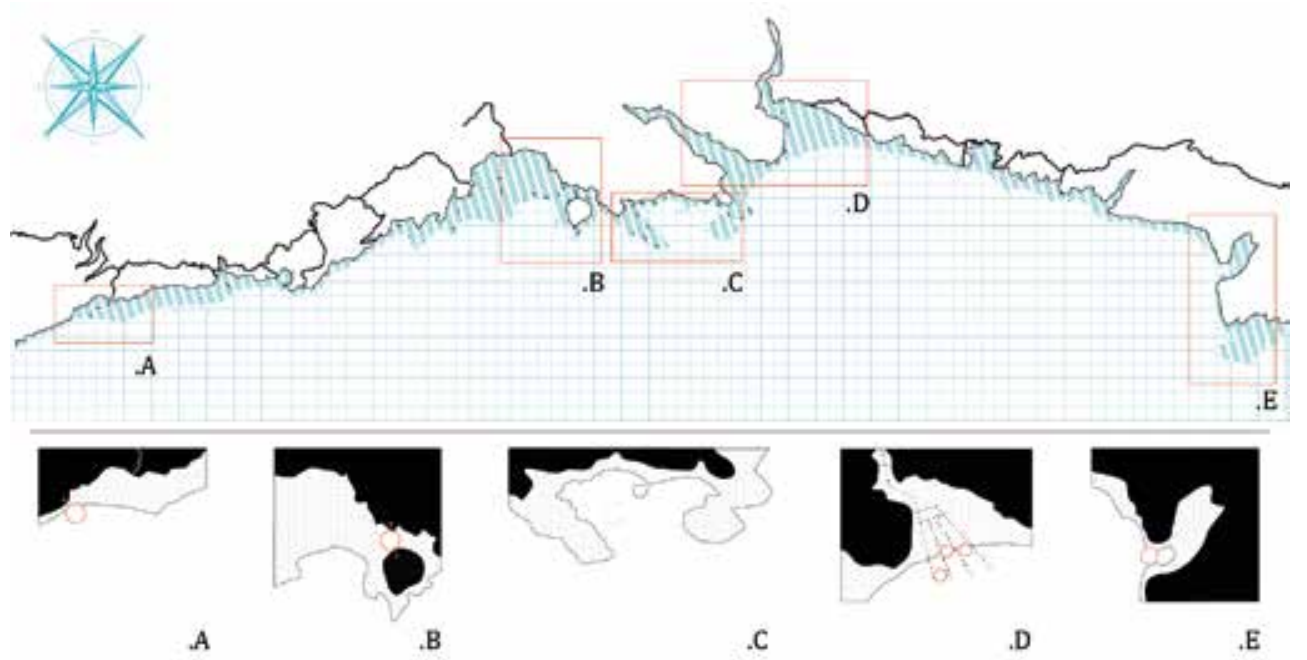

Figure 5. Above: the Riviera coastline after sea level rise. The submerged area is represented by blue and white stripes, while the red frames define the five areas selected for their morphological features. Below: taxonomy of new landscapes with the proposed floating structures.

related to infrastructural connection, touristic development and landscape conservation. Five areas, shown in Figure 5, stand out for their peculiar morphology and characteristics: the delta of the river that marks the beginning of the Riviera (A); the city centre of Himarë (B); Porto Palermo (C); Qeparo and surroundings (D); and the last promontory before Sarandë (E). For each of these areas, one prototype was designed, as described below.

\section{A. Rechargeable Theatre.}

The first case presents a floating structure that is totally isolated from the main connecting infrastructures on the mainland. The proposed floating prototype must therefore satisfy its own needs for connections and electrical power while using the landscape as a scenario for artistic representation. To achieve these aims, the movable platform houses theatrical performances and accumulates energy from renewable sources (sun, water and wind).

B. Touristic Bridge.

Himarë's promenade is mainly characterized by complementary touristic activities such as restaurants, bars and discos, while the inner part of the city is mostly dedicated to boarding facilities. If the sea level rises, the main road and promenade will be completely submerged, leaving room for the creation of a few small islands. The proposed hybrid structure intends to address two main issues related to the area: the lack of connections and the need for recreational activities. The proposed floating structure therefore supports a market and a restaurant; when in place, it can act as a physical bridge, connecting the new islands and providing 
inhabitants with basic services. This device can answer both locals' and tourists' needs, providing the lost services and linking them back to the "disconnected" Riviera.

C. Submarine museum.

Porto Palermo is considered one of the most important attractions of the area, thanks to its natural and cultural heritages. The bay is the site of both the Ali Pasha Castle and the old submarine base, while the underwater landscape presents a unique and rich ecosystem. According to the climate forecast, the whole area will become submerged, so the main idea is to transform the old submarine base into a museum, accessible by submarines. This will enable the showcasing of the underwater heritage while repurposing the existing infrastructure.

D. Aquaculture.

Qeparo valley, one of the largest plains in the country, is important for its olive tree plantations, a key agricultural resource. The main goal of this project is to transfer the productivity from land to sea in the event of a sea level rise. As the irrigation canals become redundant, they will be repurposed as anchorages for new floating devices. The designed floating prototypes will host algae and mussel cultivation, transferring the traditional terrestrial agricultural activities to the sea and adapting them to the new marine ecosystem.

\section{E. Biodiversity Observatory.}

The last segment of the Riviera hosts a fabulous cave, which private investors have tried, unsuccessfully, to exploit. The area is particularly rich in biodiversity, but due to its morphology is also hard to access. Installing floating devices for monitoring ecosystem conditions offers an opportunity to define spaces for contemplation of natural flora and fauna (Fig. 6).

The thematic floating structures listed above are all strongly committed to the idea of preserving and protecting the natural and cultural landscapes, while affecting the surroundings as little as possible. Indeed, the proposed floating structures, movable and designed to be resilient to climate change, contribute to the preservation of local identity and the promotion of the territory, thanks to the combination of the proposed and existing functions in the immediate surroundings.

\section{WHAT IF THE LAND WERE TO REPLACE THE SEA?}

Now let us consider what would happen if, shifting our point of view to the land, we metaphorically considered the land as sea.

This part of our research was centered on the investigation of architectural 

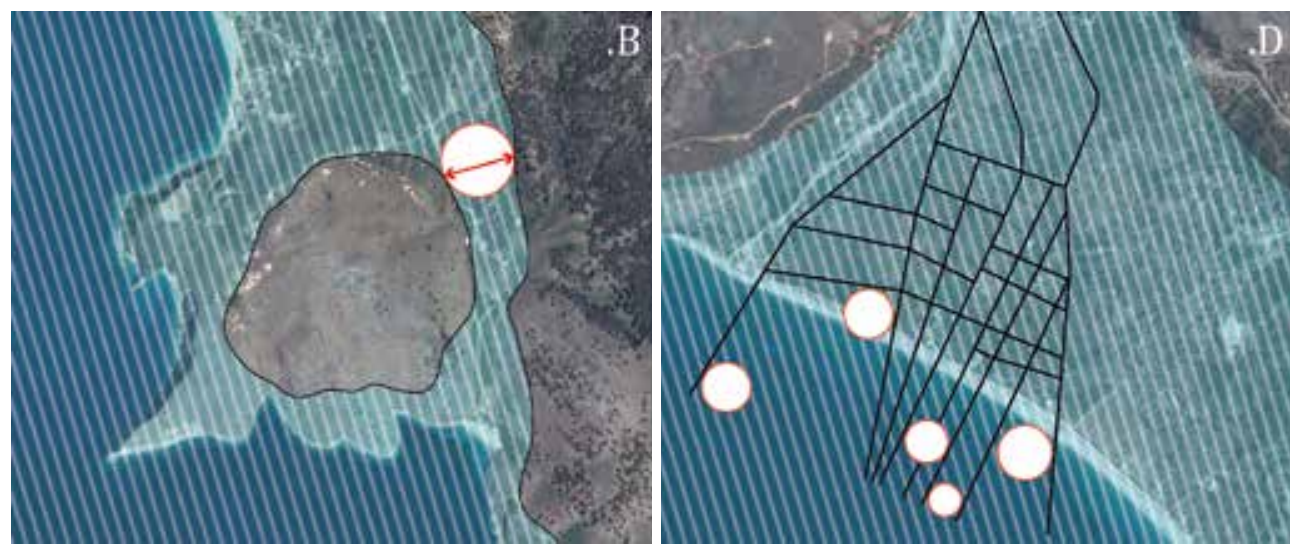

Figure 6. Scenarios proposed for the new landscapes of Himarë (B) and Qeparo (D), showing the prototypes designed for them. After the sea level rise, the Himarë promenade will be almost completely submerged and a small island will be created. The prototype aims to connect the mainland to this new island and to provide lost services. The part of Qeparo close to the sea, on the other hand, will disappear completely. The prototype aims to reinterpret agriculture, the main economic activity of the area, transposing it to the water.

consequences linked to the evolving shape of the Albanian coast. Pushing the process to the limit, the overall strategy, as well as each project, had to respond to "what if?" questions: "What if the land were to replace the sea? What if a sea level rise submerged and erased parts of the Albanian Riviera?" If the sea level really does become much higher, it will start engaging landscape architectural design with fewer fixed references. Several coastal settlements will end up being completely erased under the water. Qeparo and Borsh will disappear, while Himarë, the main urban agglomeration along the Riviera, will be submerged, although the old Himarë, given its altitude, will survive and find itself in a new relationship with the coast. The large plain, currently under human pressure imposed by vacation homes, will suddenly disappear and serve as seabed (Figs. 2 and 7).

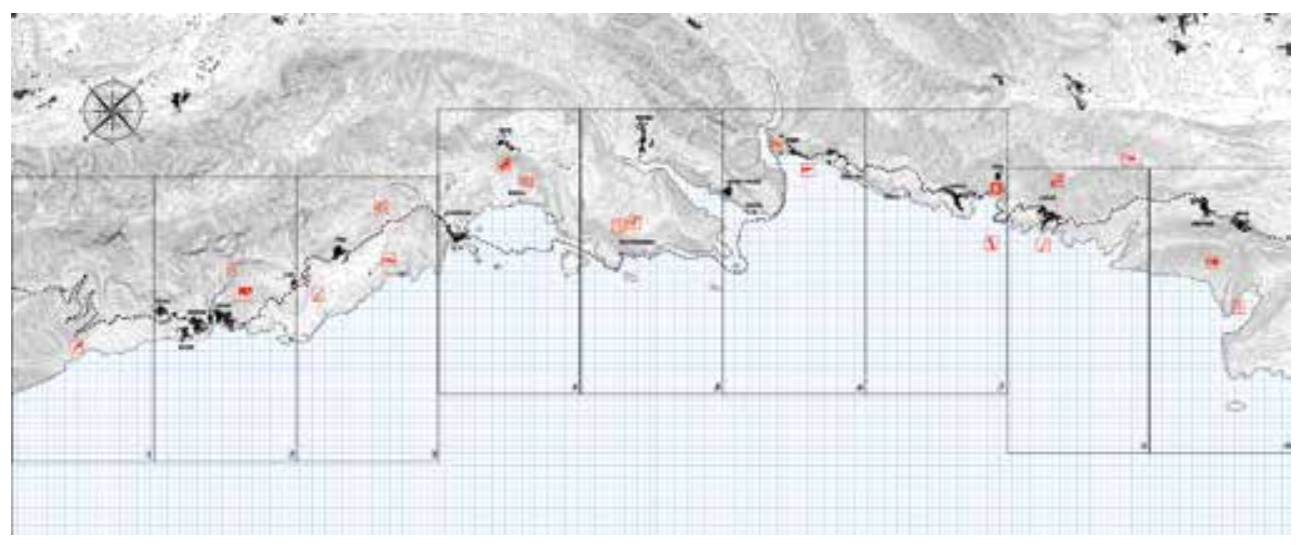

Figure 7. Cartography of a possible future Albanian Riviera, divided into nine fragments. Envisioned scenario based on the forecast sea-level rise. 
In our vision, landscape architecture is not only a "formal intervention on the topography" ${ }^{20}$ aimed at conquering a view of the horizon, but also a way for urban dwellers to access and enjoy landscape, making their human-nature relationship stronger and socially more significant.

The strategy adopted for this design speculation relies on a cartography whose base map is a selective interpretation of the Albanian geography. Every map is an invention, since the filter that establishes the features to be represented implies a design action. Our biased cartography leads to a number of experimental projects along the coast, scattered over the landscape, on town outskirts and in the centre of abandoned areas. To investigate more scenarios resulting from uncertain sea levels, we considered several possibilities. Each possible configuration was considered individually as an island and collectively as an archipelago of architectural interventions. In Gilles Deleuze's words, "It is no longer the island that is separated from the continent; it is humans who find themselves separated from the world when on an island." ${ }^{21}$ Remoteness is not a geographical feature, but is attached to the relationship between humans and nature; water is used as the principle for segregation.

The Albanian Riviera was analysed to find recurring morphological features. These geographical typologies, later addressed by each project, build up into the scientific table of the Albanian territory that we called a Tableau of Morphologies (Fig. 8a). On the one hand, the design approach can be extrapolated to other Mediterranean territories sharing the same features; on the other, in order to maintain an indissoluble bond between project and place, the architectural process (artificial shaping) starts from the form of the ground. The ultimate goal is to obtain a designed form that reacts to the natural context, establishing a joint evolutionary process.

When considering the long-term scenario, we imagined that the threshold that separates water from mainland would acquire a jagged shape.

Several former peaks near the sea will turn into groups of small islands. ${ }^{22}$ The Riviera then will become an amphibious path, especially in the coastal strip from Himarë to Borsh, where it will turn into a sea-lane. The Tableau of Morphologies (Fig. 8a) gives a numbered list of four groups of spatial conditions, each associated with a correspondingly numbered Tableau of Projects (Fig. 8b).

The first group comprises podium (1), plateau (8) and ridge (16) - these dominate from higher spots. Here we employed an expansion of the platform (1), used architecture to frame panoramic views of the landscape (8) or reinforced the ridge marking its path, culminating in a bastion-like module (16). Since the sea level rise would delineate stretched or rounded islets, reducing available dry space around the area, the architecture ought to delineate a clear border, later to become a new separation between land and water, and non-extensive modules. This way, the sea would advance but never submerge these peaks. 


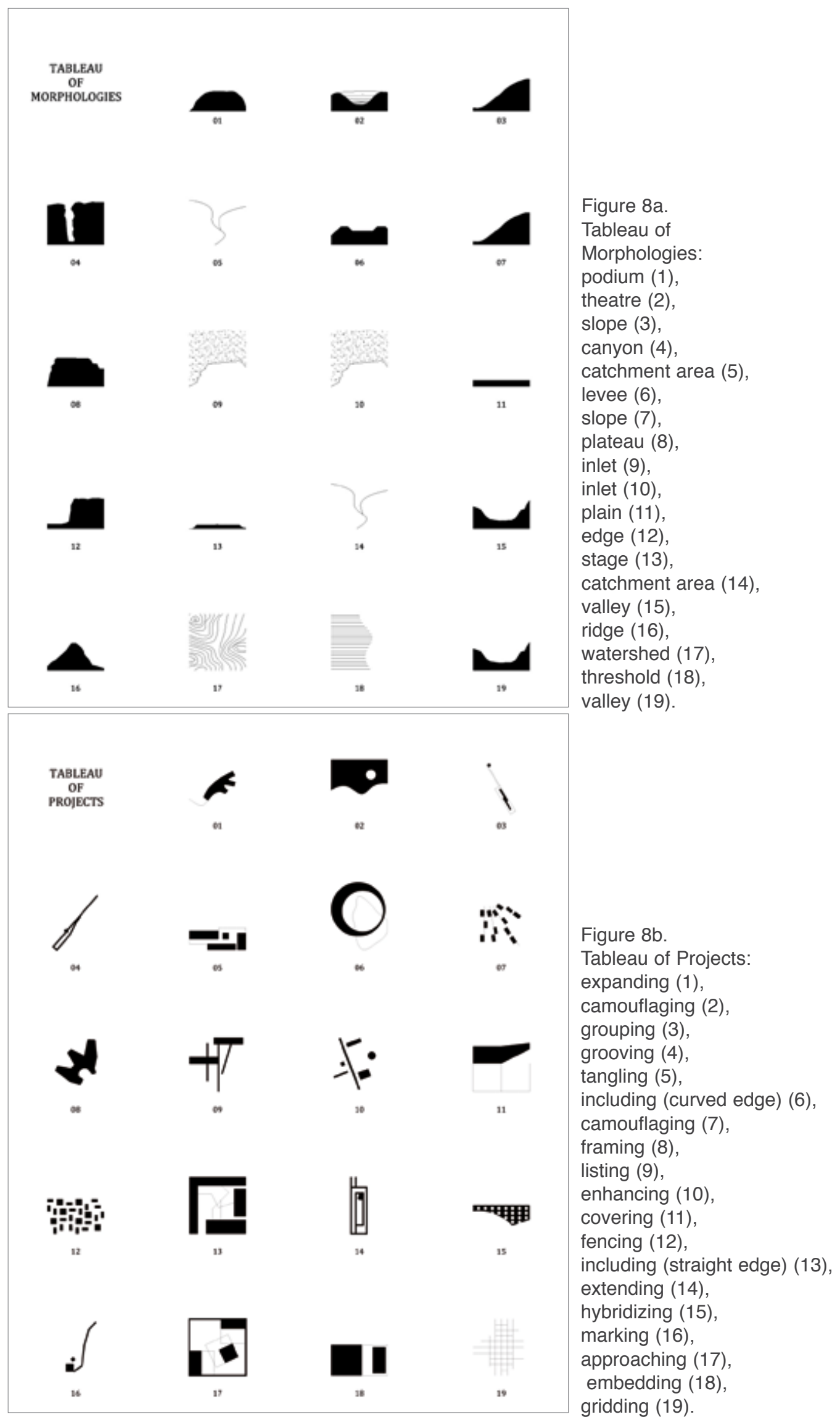


The second group comprises slope (3 and 7), canyon (4), edge (12) and threshold (18) - smooth or steep changes of altitude define wide or narrow thresholds. One can envisage the programme following a single line across the slope at different heights, or following the contours to define a set of equal-height terraces ( 3 and 7 ). In the first case, architecture emerges and challenges the drop, while in the second it camouflages artificial interventions and blends into the scenery. On the edge of the canyon we experimented with burrowing into the land, going slightly under the ground level and designing space by subtraction (4); on less steep edges, like those of a river, we scattered small private houses to let vegetation thrive and shape a bank to fight floods (12). Where the threshold marks a change between different landscapes, we conceived twofold structures. Here, the project samples different contexts and plays with inside-outside duality (18) (Fig. 9). When the sea level rises, the water will rise along the slope and

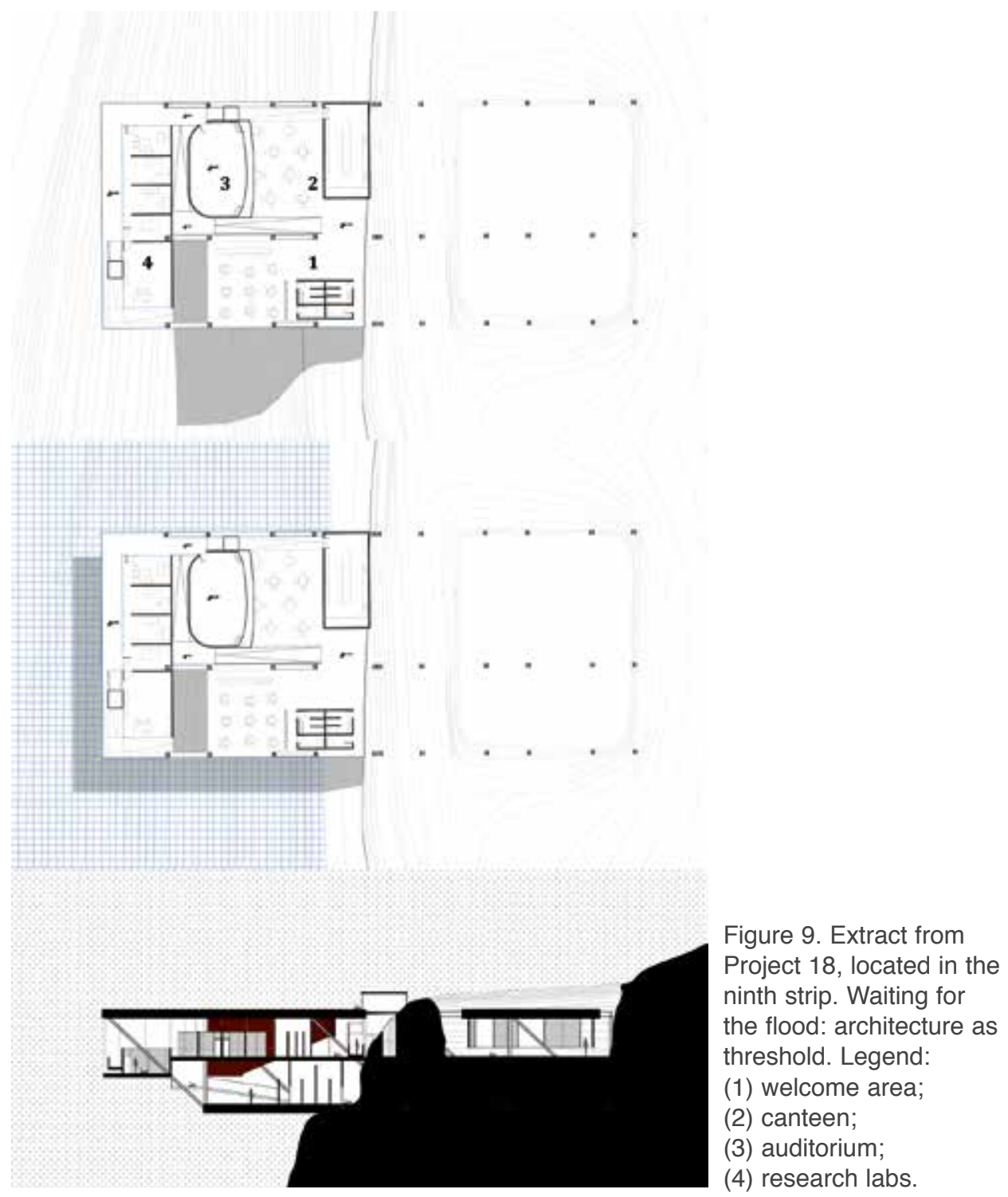


move toward new territories whose landscape design should be prepared to adapt to the new coast.

The third group is composed of inlet (9 and 10), plain (11) and stage (13) flat, even fields play with the horizon and wide views. Here we adopted a more isotropic approach to composition, giving formal recognition to programme and connections ( 9 and 10 ) and to features above and below ground (11), as well as to features inside and outside a court (13). When the sea level rises, the water will gradually invade the fields, so we employed a strict typological approach, designing the way for a building to adapt its programme to a different landscape scenario.

Finally, the fourth group includes theatre (2), catchment area (5 and 14), levee (6), valley (15 and 19) and watershed (17) - these lower altitude areas have wide territories characterized by better life conditions. Our designs included a new topography (2) and integrated water streams with leisure facilities (5, 6 and 14). They also experimented with the ways in which a multipurpose infrastructure can enhance landscape (15) (Fig. 10) or a grid adapt to complex geomorphologies (19) and devise a forestclearing sequence to build on a watershed (17). In this case, rising sea levels would create new inlets and streams, requiring adaptable elevations and buffer areas.

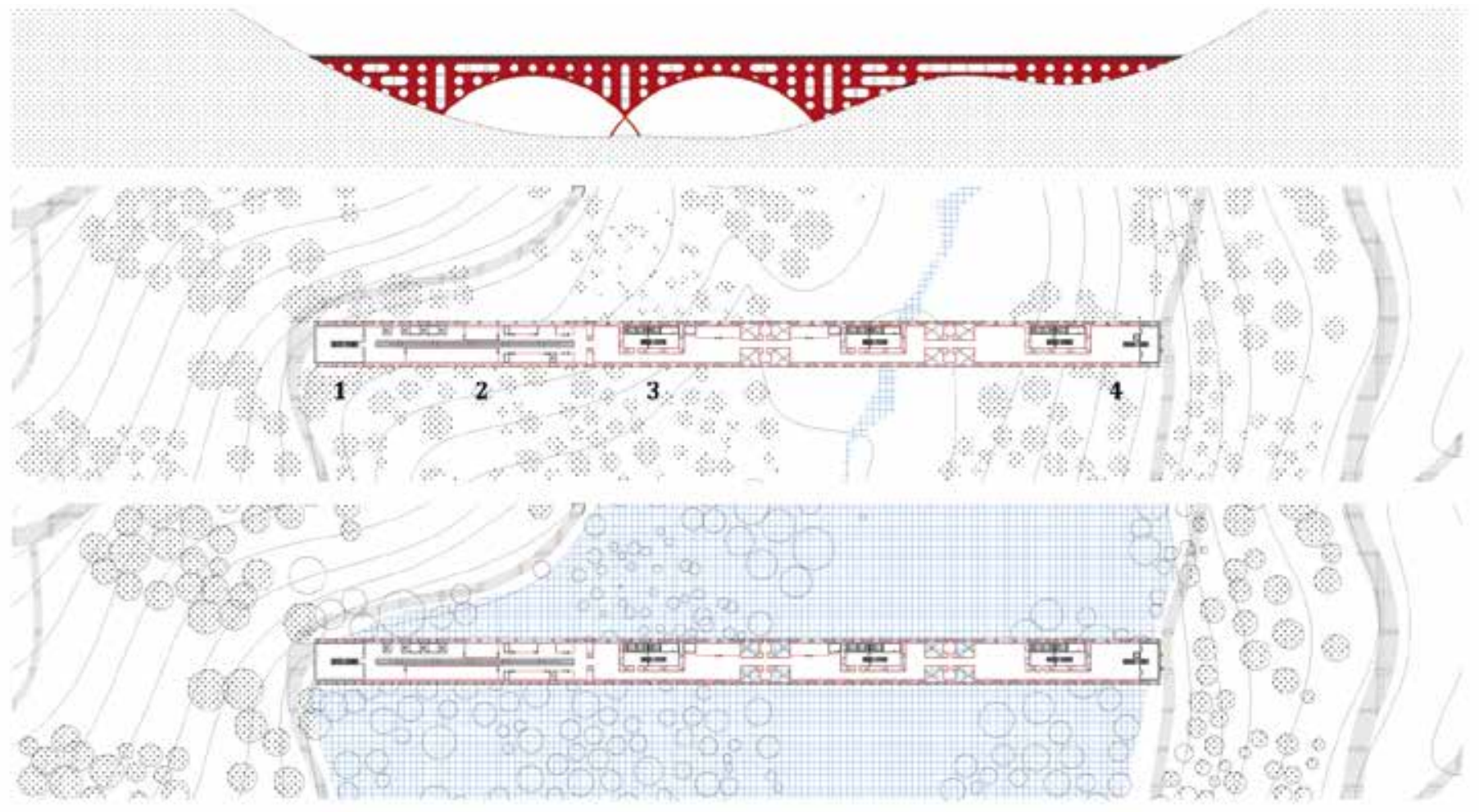

Figure 10. Extract from Project 15, located in the eighth strip. Nature infrastructure: an inhabited bridge across Mount Shendelli. Legend: (1) welcome area; (2) sports facilities; (3) common areas; (4) diving platform. 


\section{CONCLUSION}

In this paper, we have considered the natural and artificial elements that characterize the Albanian coast as an archipelago of autonomous systems capable of working in synergy, if transformed into operative fragments. Land and sea masses share negative traits, both having the capacity to erase, attack or erode their surroundings. Taking that fact as a premise, we identified these traits as backgrounds with reciprocal interdependence. Each background was then considered as an interchangeable element in the framework of design approaches; these either operate on the sea as if it were land, or metaphorically assign the characteristics of the sea to the land "What if the sea were to replace the land? What if we were to consider the land as if it were sea?" The process followed in the speculative design operations on the Albania Riviera is based on two creative interpretative keys that we named "landscape fragments" and "landscape within a landscape." The design process then followed a two-step approach in which operative artificial and natural morphological traits were identified and selected before being overlaid with landscape projects.

Concepts of adaptation and flexibility were introduced to explore future design approaches for the Albanian coast. These approaches consider the unpredictability of natural and social phenomena and the dynamic character of landscape. To deal with the concept of mutation and instability, we approached the projects as islands in a sea of water or greenery. This concept has resulted in projects that dealt with the concept of hybridity in architecture (floating islands that act as extensions of the land), and in speculative design investigations based on multiple scenarios, where the concept of "selection" on an active topography was applied to a system of architectural objects. Each of these reacts to the natural context, where each configuration is considered individually as an island and collectively as an archipelago of architectural interventions. The two examples shown in Figure 9 and Figure 10 present architectural solutions that adapt to the continuous mutations of the sea and the land. These projects also show how new land configurations reveal new architectures with a strong autonomous character but, at the same time, establish a functional network with the existing villages of the Albanian Riviera.

The architectural speculations presented in this essay not only open new debates on the resilience of the Albanian coastline, but also address the important issue of topographic representation and graphical interpretation as tools to reveal hidden characteristics of the landscape. Indeed, the design experimentations discussed in this paper show how, through a set of "tactical selections" in the landscape, we can re-establish relationships between land morphologies and design actions. 


\section{Notes}

1. Fernand Braudel, The Mediterranean and the Mediterranean World in the Age of Philip II, vol. I, 7th ed. (Berkeley CA, USA: University of California Press, 1972), 99. First published 1949, La Méditerranée et le monde méditerranéen à l'époque de Philippe II.

2. Oswald Mathias Ungers et al., The City in the City. Berlin: A Green Archipelago (Zurich, Switz.: Lars Müller Publishers, 2013).

3. The brand "Riviera" is used for the first time during the "communist period," attempting to recall the successful touristic destinations cases of France and Italy. In the 1960s, it appears in travel guides and diaries such as: Guide d'Albanie (avec un petit Manuel de conversation) edited by Albturist (the state travel agency) in 1958 and the travel diary by Albert Mahuzier, who travelled in Albania in 1965 and wrote L'Albanie entrouvre sus frontieres.

4. Romeo Eftimi, "Some Considerations on Seawater-Freshwater Relationship in Albanian Coastal Area," in Coastal Aquifers Intrusion Technology: Mediterranean Countries, eds. Juan Antonio Lopez-Gaeta et al. (Instituto Geologico y Minero de España - IGME: Madrid, 2003).

5. Riviera competition Website: http://competitions.planifikimi.gov.al/riviera/.

6. The Observatory of the Mediterranean Basin (OMB) is a research unit dedicated to finding, along the Albanian coast, relevant topics linked to water and land characterization in Albania, developing and sharing design practice and research projects.

7. For more info on the previous studies see: Besnik Aliaj and Loris Rossi, eds., Albanian Riviera: An Alternative Model of Progress and Development for Next Generation Albania (Tirana, Alb.: Mali Pleshti, 2016).

8. Regarding the Albanian historical transformation with a focus on Tirana see: Besnik Aliaj, Keida Lulo and Genc Myftiu, Tirana: The Challenge of Urban Development (Tirana, Alb.: Cetis edition, 2003).

9. See note 2 .

10. Within the political and architectural debate beyond the word archipelago see: Pier Vittorio Aureli, The Possibility of an Absolute Architecture (Cambridge MA, USA: MIT Press, 2011) and Massimo Cacciari, L'arcipelago (Milan: Adelphi, 1997).

11. To examine this matter further, see: Galo Canizares, "Exquisite Corpses: An Architectural Mistery" (MArch thesis, MIT, 2014), https://dspace.mit.edu/handle/1721.1/89939.

12. Oxford Dictionaries Online, s.v. "Selection," https://en.oxforddictionaries.com/definition/ selection.

13. Christo Vladimirov Javacheff is an American artist, born in Bulgaria (1935). His wife, Jeanne-Claude Marie Denat, was an American artist born in France (1935-2009). The couple worked together on environmental works of art since the 1970s.

14. See note 2, 16.

15. The representative case studies underpinning the theoretical investigation were developed by students in the architecture graduate design studios and in the Master of Landscape and Urban Design of the Department of Applied Research at Polis University during the academic years 2015-16 and 2016-17. In particular, during the courses: Design Studio and Theory of Architecture IV, themed "Network Archipelago. New Interpretative Tools to Promote the Albanian Riviera Landscape" (Lecturer: Dr. Loris Rossi; Assistant Lecturers: Laura Pedata, Enrico Porfido, Giuseppe Resta), and the Landscape and Urban Design Studio, themed "Ephemeral Landscape: Temporary and Flexible Interventions for Promoting the Coastline Development and Valorizing the Natural Landscape," 2015-16 (Lecturer: Dr. Loris Rossi; Assistant Lecturers: Enrico Porfido, Caterina Spadoni).

16. Marta Marcos and Michael N. Tsimplis, "Comparison of Results of AOGCMs in the Mediterranean Sea during the 21st Century," Journal of Geographic Research 113, C12028 (December 2008), doi:10.1029/2008JC004820.

17. Robert J. Nicholls and Stephen Parker Leatherman, "Global Sea Level Rise," in As

Climate Changes: Potential Impacts and Implications, eds. Kenneth M. Strzepek, and Joel B. Smith (Cambridge, UK: Cambridge University Press, 1994), 92-123.

18. See notes 4 and 17.

19. See note 15

20. See an account of this duality in Clemens Steenbergen, "Metropolitan Footprints," in

The Architecture Annual 2006-2007: Delft University of Technology, ed. Henco Bekkering (Rotterdam: 010 Publishers, 2008).

21. Gilles Deleuze, Desert Islands and Other Texts 1953-1974, ed. David Lapoujade (Los Angeles: Semiotext(e), 2004), 10.

22. Albania has only one island: Sazan, near the city of Vlore. 


\section{References}

Aliaj, Besnik and Loris Rossi, eds. Albanian Riviera: An Alternative Model of Progress and Development for Next Generation Albania. Tirana, Alb.: Mali Pleshti, 2016.

- - . Albania's New Sustainable Image. Branding Tirana-Rinas Corridor. Tirana, Alb.: Pegi Edition, 2015.

Aliaj, Besnik, Eranda Janku, Ledio Aalkja, and Sotir Dhamo. "Albania 2030" Manifesto. A National Spatial Development Vision. Tirana, Alb.: Polis Press, 2014.

- - Keida Lulo, and Genc Myftiu. Tirana, the Challenge of Urban Development. Tirana, Alb.: Cetis Edition, 2003.

Aureli, Pier Vittorio. The Possibility of an Absolute Architecture. Cambridge MA, USA: MIT Press, 2011.

-- , ed. The City as a Project. 3rd ed. Berlin: Ruby Press, 2016.

Buda, Alex et al. Guide d'Albanie (avec un petit Manuel de conversation). Tirana, Alb.: Albturist, 1965.

Declerck,Joachim, Bart Melort, Marc Ryan and Martino Tattara, eds. Tirana Metropolis. Rotterdam: Berlage Institute, 2004.

Bhatia, Neeraj, and Mary Casper. The Petropolis of Tomorrow. New York: Actar, 2013.

Braudel, Fernand. II Mediterraneo: Io spazio, la storia, gli uomini, le tradizioni. Milan: Bompiani, 2014. First published 1977, La Méditerranée: l'espace et l'histoire.

- - . The Mediterranean and the Mediterranean World in the Age of Philp II. Vol. I. Berkeley CA, USA: University of California Press, 1972. First published 1949, La Méditerranée et le monde méditerranéen à l'époque de Philippe II.

Cacciari, Massimo. L'arcipelago. Milan: Adelphi, 1997.

Callejas, Luis. Islands \& Atolls. Series Pamphlet Architecture, 33. New York: Princeton Architectural Press, 2013.

Canizares, Galo. "Exquisite Corpses: An Architectural Mistery." MArch thesis, MIT, 2014.

Ciorra, Pippo, Francesco Garofalo, and Piero Ostilio Rossi. ROMA 20-25. New Life Cycles for the Metropolis. Rome: Quodlibet, 2015.

Deleuze, Gilles. Desert Islands and Other Texts 1953-1974. Edited by David Lapoujade. Los Angeles: Semiotext(e), 2004.

Eftimi, Romeo. "Some Considerations on Seawater-Freshwater Relationship in Albanian Coastal Area." In Coastal Aquifers Intrusion Technology: Mediterranean Countries, edited by Juan Antonio Lopez-Gaeta et al. Instituto Geologico y Minero de España - IGME: Madrid, 2003.

Focillon, Henri. Vita delle forme. Seguito da Elogio della mano. Edited by Enrico Castelnuovo. Turin: Einaudi, 2002.

Gorgeri, Fabiola. Frammenti in architettura. Durata e mutamento. Florence: Edifir Edizioni Firenze, 2015.

Harris, William Vernon. Rethinking the Mediterranean. Oxford, UK: Oxford University Press, 2005.

Insolera, Italo. "L'uomo e la costruzione dell'ambiente." In Roma, per esempio: le città e l'urbanista, 5-17. Rome: Donzelli Editore, 2010.

Koolhaas, Rem, and Hans Ulrich Obrist. Project Japan: Metabolism Talks. Cologne, Ger: Taschen, 2011.

Kostof, Spiro. The City Shaped. Urban Patterns and Meanings Trough History. New York, Boston, London: Bulfinch Press, 1991.

Lambert, Leopold. "\#Liberty Square///The Archipelago as a Territorial Manifesto." The Funambulits. Bodies, Design \& Politics (blog). November 1, 2011. https://thefunambulistdotnet.wordpress.com/2011/11/01/liberty-square-the-archipelagoas-a-territorial-manifesto/.

Lodoli, Marco. Isole: guida vagabonda di Roma. Turin: Einaudi, 2005.

Mahuzier, Albert. L'Albanie entrouvre sus frontieres. Paris: Presses de la cité, 1965.

Marcos, Marta and Michael N. Tsimplis. "Comparison of Results of AOGCMs in the Mediterranean Sea during the 21st Century." Journal of Geographic Research 113, C12028 (December 2008). doi: 10.1029/2008JC004820.

Matvejevíc, Predrag. Breviario mediterraneo. Milan: Garzanti, 2004.

Nicholls, Robert J. and Stephen Parker Leatherman. "Global Sea Level Rise." In As Climate Changes: Potential Impacts and Implications, edited by Kenneth M. Strzepek, and Joel B. Smith, 92-123. Cambridge, UK: Cambridge Univ. Press, 1994. 
Rossi, Loris. "International Workshop Tirana Interrupted." Loris Rossi Architect (blog). http://lorisrossi.com/student-work/workshop/.

- - . "Mobilicity. Tirana multimodal station." Forum $A+P 12$ (2013): 28-35.

- - . "Tirana Interrupted." FORUM A+P 16 (2015): 78-87.

Steenbergen, Clemens. "Metropolitan Footprints." In The Architecture Annual 2006-2007: Delft University of Technology, edited by Henco Bekkering. Rotterdam: 010 Publishers, 2008.

Stoppani, Teresa. Paradigm Islands: Manhattan and Venice. Discourses on Architecture and the City. Abingdon, UK; New York: Routledge, 2011.

Ungers, Oswald Mathias. Morphologie = City Metaphors. Cologne, Ger; Walter Koning, 2011.

- -, Rem Koolhaas, Peter Reimann, Hans Kollhoff, and Arthur Ovaska. The City in the City. Berlin: A Green Archipelago. Zurich, Switz.: Lars Müller Publishers, 2013.

\section{Acknowledgments}

The case studies underpinning the theoretical investigation were developed by graduate students in Architecture and Landscape Design Studios, and through research activities of the Department of Applied Research at Polis University, Tirana (Albania).

\section{Credits}

Figures 1, 2, 4-8b: images by the Authors.

Figure 3: maps created by students Xhoana Kristo, Agon Dalladaku and Ardita Sylaj. Figure 9: image by student Gent Shehu.

Figure 10: image by student Asdren Sela.

Loris Rossi is an architect and full time Lecturer at Polis University, Tirana (AL), where he is Head of the Applied Research Department and Director of the Observatory of the Mediterranean Basin. At La Sapienza University (Rome), he obtained his MArch (2004) and a PhD scholarship through which he was visiting scholar at the Department of Urban Planning at UCLA. He was principal of the Rome based "ungroup" architecture office (20052011). He was Adjunct Professor at La Sapienza (2011), Dean of the School of Planning and Urban Design at Polis University (2012-13), and Visiting Faculty at the UCLA Department of Architecture \& Urban Design (January 2015). E-mail: Ioris_rossi@universitetipolis.edu.al

Laura Pedata is a Lecturer in Landscape Architecture and Sustainable Design at Polis University, Tirana (AL) and candidate in the International Doctorate in Architecture and Urban Planning, Ferrara + Polis Universities. Laura graduated in 2005 at La Sapienza University (Rome) and is a licensed architect since 2007. She co-founded the architecture office "ungroup" in Rome. In 2007, with a Fulbright Scholarship she attended a Master in Architecture Program (MArchII) at UCLA. She was Adjunct Professor at La Sapienza (2009-2011) and in 2012 she worked for SOM in San Francisco.

E-mail: laura_pedata@universitetipolis.edu.al

Enrico Porfido is a PhD candidate and lecturer at Polis University, Tirana. He is a licensed architect graduated from Ferrara University (2015). With a study period at the Oslo School of Architecture (2013) and after working with ClusterTheory and PROAP studio (2012), he founded pais(vi)agem with Claudia Sani (2014). After graduation, he collaborated with Sealine - a departmental research unit in Ferrara University. He was recently invited as external valuation expert in the Landscape Master of Polytechnic University of Catalonia (Barcelona). E-mail: enrico_porfido@universitetipolis.edu.al

Giuseppe Resta is a licensed architect graduated from the Politecnico di Bari (2013) and a $\mathrm{PhD}$ candidate at the Università degli Studi RomaTRE (Rome). He is a Teaching Assistant at the Politecnico di Bari (2014-2017) and Polis University (2017). Resta has been architecture editor at Artwort magazine and Artwort.com. His work has been published on architectural magazines such as STUDIO, Lunch journal, T3xture, Architecture and Urban Planning, Inflection. He has been co-curator for Evoked. Architectural Diptychs (Tirana, 2016), Land(e)scape (Napoli, 2016), and the research project "Spontaneous" (since 2017). E-mail: giusepperesta.arch@gmail.com 